\title{
Leontiasis Ossea Following Secondary Hyperparathyroidism and Hemodialysis
}

\author{
Pooneh Dehghan1, Ali Zahiri1* ${ }^{*}$, Mohammad Ali Karimi' ${ }^{1}$, Mohammad Hossein Ghadiani2 \\ ${ }^{1}$ Department of Radiology, Taleghani Hospital, Shahid Beheshti Medical University, Tehran, Iran \\ ${ }^{2}$ Department of Nephrology, Taleghani hospital, Shahid Beheshti Medical University, Tehran, Iran \\ Email: Poonehdehghan@yahoo.com, ${ }^{*}$ dr alizahiri@yahoo.com, mkarimidr@yahoo.com, \\ mhghadiani1347@yahoo.com
}

Received 18 June 2015; accepted 11 July 2015; published 14 July 2015

Copyright (C) 2015 by authors and Scientific Research Publishing Inc.

This work is licensed under the Creative Commons Attribution International License (CC BY).

http://creativecommons.org/licenses/by/4.0/

(c) (i) Open Access

\begin{abstract}
Leontiasis ossea is a rare medical condition which is characterized by an overgrowth of the facial and cranial bones secondary to chronic renal failure and secondary hyperparathyroidism. We reported a case of leontiasis ossea with history of secondary hyperparathyroidism due to end-stage renal disease on regular hemodialysis. A 37-year-old female with end-stage renal disease from lupus disease on regular hemodialysis complaining of progressive facial deformity for two years causing dyspnea, dental malocclusion and dysarthria with the final diagnosis of uremic leontiasis ossea. It is important to recognize features of leontiasis ossea, as it may result in life-threatening upper airway obstruction and compressive cranial neuropathy while after parathyroidectomy, facial changes can be stabilized or improved mildly.
\end{abstract}

\section{Keywords}

\section{Hyperparathyroidism, Hemodialysis, Leontiasis Ossea}

\section{Introduction}

Findings of renal osteodystrophy in cranial bones are not uncommon and include osteomalacia, osteosclerosis, erosion of the cortical bone, brown tumors and resorption of the lamina dura. However, massive thickening of the cranial vault and facial bones, called uremic leontiasis ossea (ULO), has been reported to be quite rare [1]. ULO is a descriptive term applied to hyperostotic changes in the facial bones that can result in bilateral expansion of the malar processes, thus reducing the nasomaxillary angle. The term leontiasis was initially used to describe changes in the facial skin observed in patients with leprosy. Such chronic indurative cutaneous changes,

\footnotetext{
${ }^{*}$ Corresponding author.
}

How to cite this paper: Dehghan, P., Zahiri, A., Karimi, M.A. and Ghadiani, M.H. (2015) Leontiasis Ossea Following Secondary Hyperparathyroidism and Hemodialysis. Journal of Biosciences and Medicines, 3, 54-59. 
as opposed to bony overgrowth, induce a lion-like facial expression [2]. Pathologic specimen of leontiasis ossea shows severe osteitis fibrosa. Leontiasis ossea (bighead disease) is similar to fibrous dysplasia. The distinction between leontiasis ossea and other conditions with similar appearances is actually made by clinical and laboratory findings [3]. In addition to craniofacial fibrous dysplasia the following conditions may mimic leontiasis ossea: Paget disease, gigantism, craniosynostosis, tumors of the paranasal sinuses, syphilitic osteoperiostitis and uremia with secondary hyperparathyroidism. The facial appearances resemble features of Lion face in Leprosy and the nomenclature "Leontiasis Ossea" points to this resemblance. This clinical condition is frequently manifested by progressive enlargement of the maxillary and other facial bones leading to encroachment upon the orbital, oral and nasal cavity with its accessory sinuses. Osseous overgrowth may result in exophthalmos and optic nerve compression. Massive hyperostosis of the cranial vault and facial bones may rarely be global with irreversible consequences [4].

Pathophysiological origin of the disease is not clearly understood. However, nutritional and secondary hyperparathyroidism due to uremia has been suggested as major etiologies for the disease [5]. After parathyroidectomy, facial changes can be stabilized or improve mildly.

Herein, we reported a case of uremic leontiasis ossea with prior history of secondary hyperparathyroidism due to end-stage renal disease and regular hemodialysis.

\section{Case Presentation}

A 37-year-old female with end-stage renal disease from lupus disease on regular hemodialysis presented to the emergency room complaining of worsening facial deformity over the past two years now causing dyspnea, dental malocclusion and dysarthria. Physical exam revealed marked non-tender maxillary and mandibular hypertrophy with nasal flattening, wide-spaced teeth and severe palatal changes. Laboratory findings were consistent with severe hyperparathyroidism (markedly elevated PTH level, phosphorus and alkaline phosphatase with nearly normal calcium level) (Table 1). Bone densitometry of patient shows osteoporosis according to WHO classification (Table 2). Ultrasound reveals right inferior parathyroid adenoma measuring $15 \times 10 \mathrm{~mm}$. In whole body bone scan by $99 \mathrm{~m}$-Tc-MDP, both maxilla and mandible from mentum to both mandible angles demonstrate hyperplasia with very intense hyperactivity which can imply aggressive hyperostosis, metabolic infiltrates (like as Paget's disease) and fibrous dysplasia. In lateral skull radiograph (Figure 1), enlargement of both maxilla and mandible with ground glass appearance and loss of corticomedullary differentiation concomitant with deformity of the alveolar ridge and teeth with absence of Lamina Dura are seen. CT of the face (Figures 2-4) shows extensive hyperostosis and demineralization of the mandible, maxilla and skull with characteristic appearance of diffuse bone tunnels. Skull CT (Figures 2-4) shows severe overgrowth of diploic space with ground glass appearance and loss of corticomedullary differentiation leading to deformity, compression of cerebral tissue and narrowing of the upper airways and skull base neurovascular foramina. Hyperostosis of facial and cranial bones and ground-glass expansion of the maxilla, mandible, and skull with bone tunnels are evident as characteristics of uremic leontiasis ossea. In 3D-CT imaging (Figure 3), deformity of maxilla and mandible with encroachment upon the orbital, oral and nasal cavities are also showed. Severe hypertrophy of hard palate with severe narrowing of oropharyngeal airway is quite striking (Figure 4).

Table 1. Laboratory data.

\begin{tabular}{|c|c|c|c|c|}
\hline & Test & Result & Normal range & Unit \\
\hline$*$ & BUN & 40 & $7-20$ & $\mathrm{mg} / \mathrm{dl}$ \\
\hline$*$ & Creatinine & 5.8 & $0.5-1.1$ & $\mathrm{mg} / \mathrm{dl}$ \\
\hline$*$ & Uric acid & 6.2 & $2.4-6$ & $\mathrm{mg} / \mathrm{dl}$ \\
\hline$*$ & Calcium & 8.3 & $8.5-10.2$ & $\mathrm{mg} / \mathrm{dl}$ \\
\hline$*$ & Phosphorus & 6.2 & $2.4-4.1$ & $\mathrm{mg} / \mathrm{dl}$ \\
\hline$*$ & PTH & 2780 & $10-55$ & $\mathrm{pg} / \mathrm{ml}$ \\
\hline$*$ & Alkaline phosphatase & 478 & $44-147$ & $\mathrm{U} / \mathrm{L}$ \\
\hline$*$ & $\mathrm{Na}$ & 136 & $135-145$ & $\mathrm{mEq} / \mathrm{L}$ \\
\hline$*$ & $\mathrm{~K}$ & 4.1 & $3.5-5.2$ & $\mathrm{mEq} / \mathrm{L}$ \\
\hline
\end{tabular}




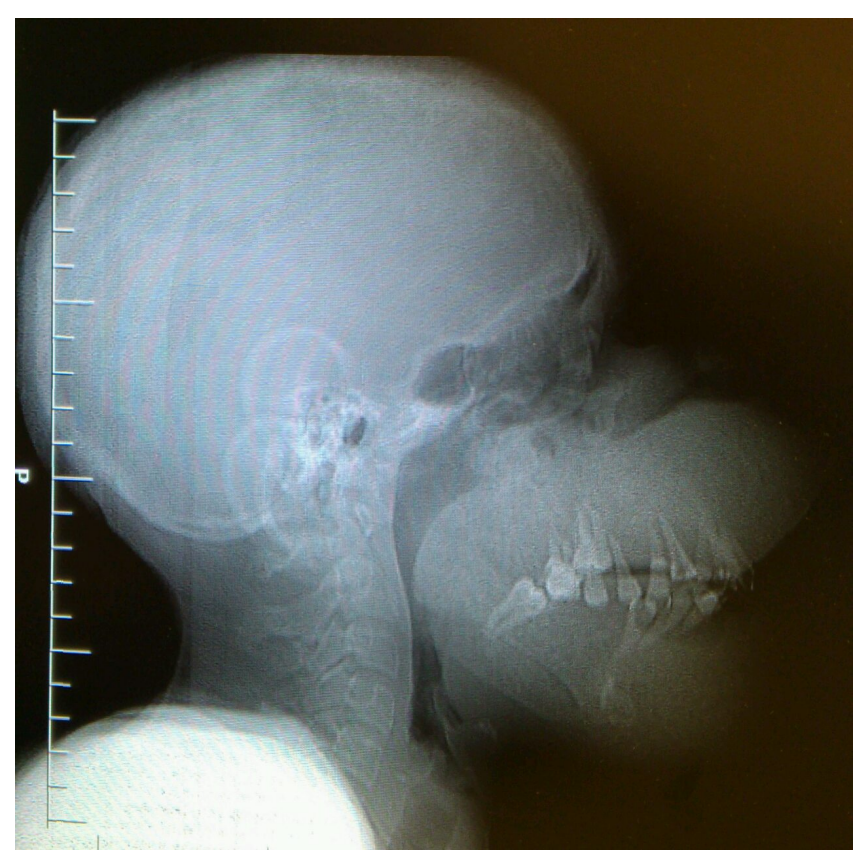

Figure 1. Lateral skull radiography reveals enlargement of both maxilla and mandible with ground glass appearance and loss of corticomedullary differentiation concomitant with dental malocclusion and absent Lamina Dura. Of note is narrowing of the oropharyngeal space.

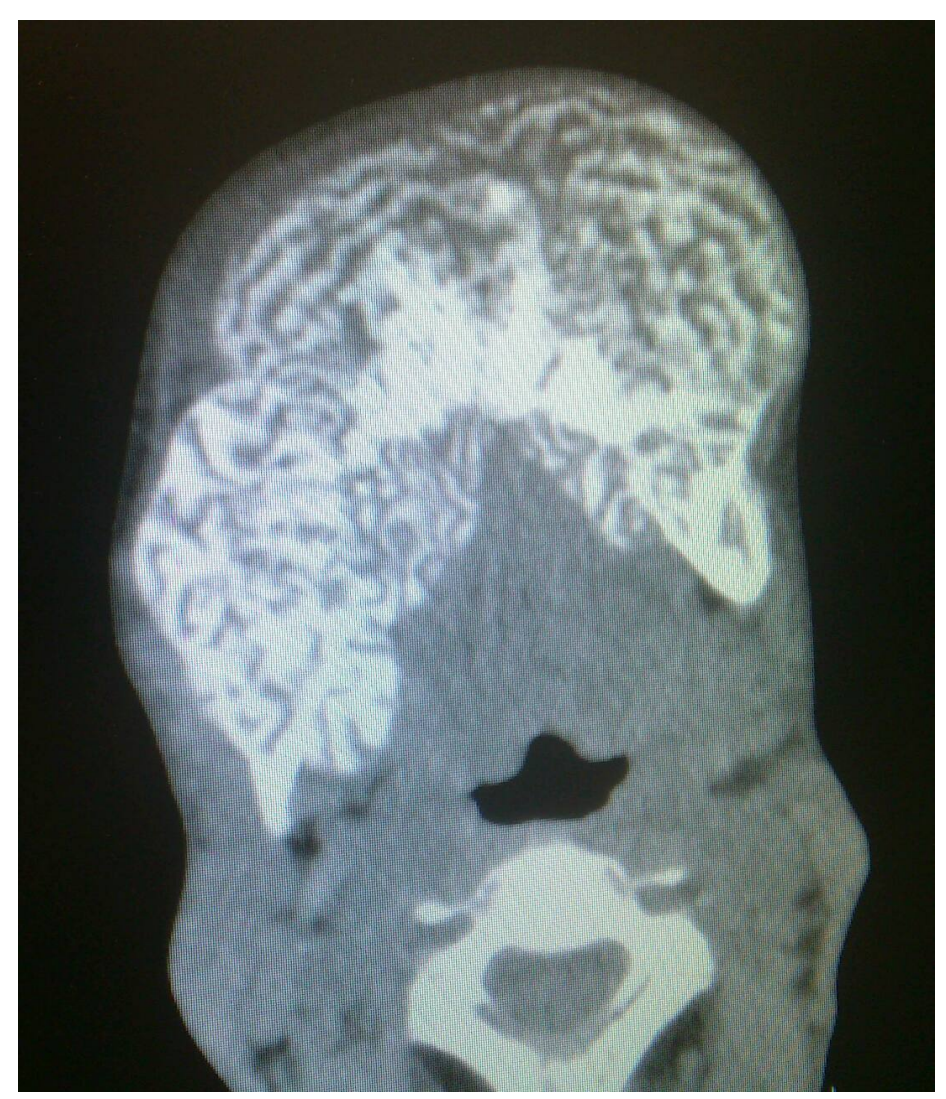

Figure 2. Axial CT of the face shows extensive bone growth with demineralization of the mandible with characteristic appearance of diffuse bone tunnels. 


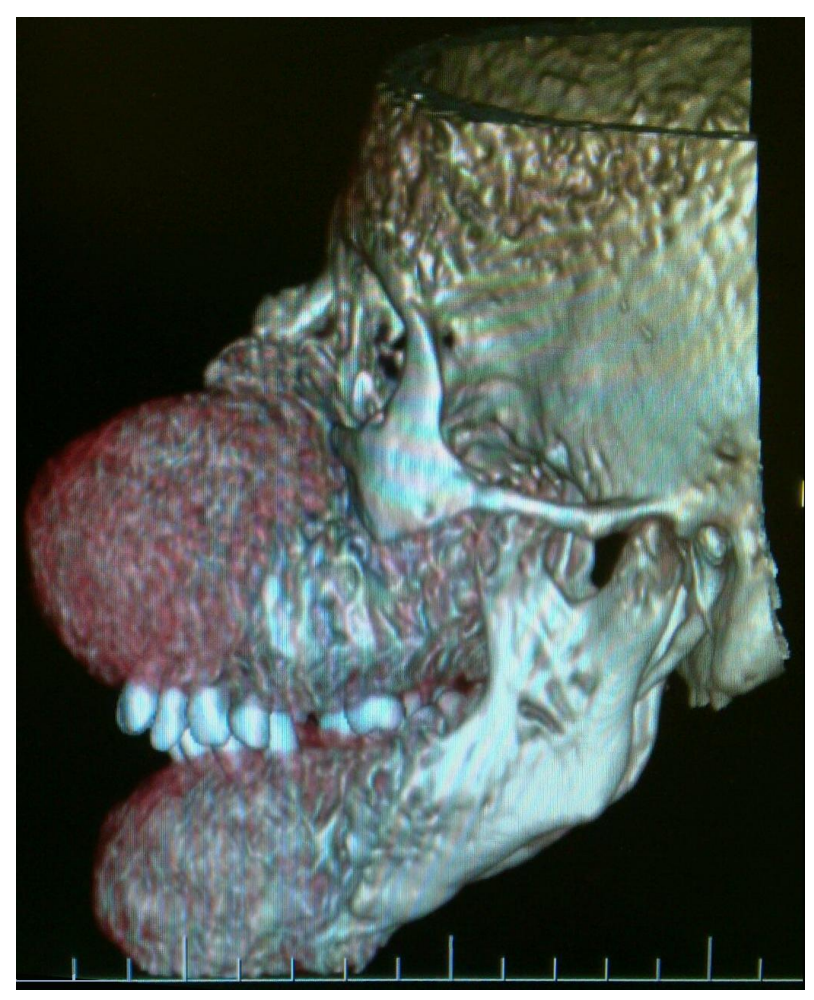

Figure 3. 3D reformatted CT image: deformity of maxilla and mandible with encroachment upon the orbital, oral and nasal cavities.

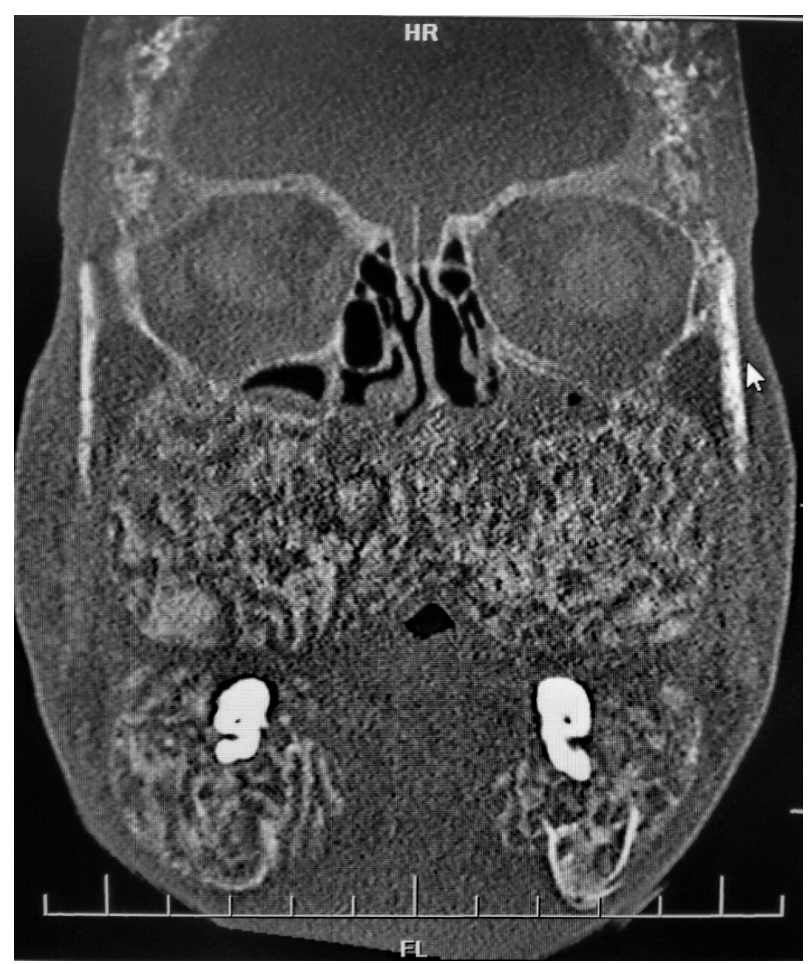

Figure 4. Coronal CT scan of face and skull: Hyperostosis of facial and cranial bones and ground-glass expansion of the maxilla, mandible and skull with bone tunnels are shown as consistent with uremic leontiasis ossea. Marked hypertrophy of the hard palate with significant narrowing of the oropharyngeal space are shown beautifully. 
Table 2. Bone densitometry.

\begin{tabular}{cccc}
\hline Scan & $\mathbf{B M D}\left(\mathbf{g} / \mathbf{c m}^{\mathbf{2}}\right)$ & T-score & Z-score \\
\hline Lumbar Spine & 0.468 & -5.3 & -5.1 \\
Total Femur & 0.354 & -4.8 & -4.7 \\
Femoral neck & 0.292 & -5.0 & -4.8 \\
\hline
\end{tabular}

Bone specimen from biopsy was sent to the pathology department. Pathologic report revealed a fibro-osseous lesion containing irregular curved bone spicules within fibrous tissue. Large resorptive lacunae filled with multiple osteoclasts, and areas of increased osteoid covered with numerous osteoblasts are also seen. That was finally reported as fibrous dysplasia. Similar pattern in pathology is often seen in both conditions (fibrous dysplasia and leontiasis ossea) so clinical, laboratory and imaging findings can help differentiate them and the final diagnosis was made by the clinical and imaging features. Parathyroidectomy is scheduled for patient's treatment. After a successfull parathyroidectomy, calcium, vitamin D, iron supplement and folic acid are administrated for patient. Four months later, deterioration of patients' head and face appearance is stopped. Some improvement in upper airway symptoms is noted. The patient is following now.

\section{Discussion}

End-stage renal failure especially concurrent with continuous hemodialysis is a common cause of bone metabolism alteration. Patients suffering from this clinical condition face phosphate retention and reduced vitamin D conversion leading to hypocalcaemia that induce PTH over-secretion. Moreover, following hemodialysis, failure to adequately manage phosphate and calcium can result in severe hyperparathyroidism leading to marked osteodystrophy [5] [6]. Findings in secondary (and tertiary) hyperparathyroidism are numerous: sub periosteal bone resorption, osteopenia, osteosclerosis e.g. rugger-jersey spine, soft tissue calcification, generalized increased uptake on Tc-99m pertechnetate bone scan, superior and inferior rib notching, Brown tumors, terminal tuft erosion and "salt and pepper" appearance of the skull. Facial skeletal changes associated with hyperparathyroidism are infrequently encountered and assume 3 radiographic patterns [7] [8]. The classic form is termed "osteitis fibrosa cystica" and presents with a combination of increased osteoblast activity, peritrabecular fibrosis, and cystic brown tumors [6]. Radio graphically, this appears as a constellation of cortical thinning of multiple bones, coarse trabecular patterns, osteolytic lesions, and "salt-and-pepper" appearance of the skull which is the result of mixed osteolytic and sclerotic osseous involvement [5] [9] [10]. The second form resembles fibrous dysplasia, with a classic ground-glass pattern on both conventional films and CT. Unlike true fibrous dysplasia, these findings can be diffuse and generalized, with poor corticomedullary distinction, an imaging finding not present in fibrous dysplasia. The 3rd and rarest form is uremic leontiasis ossea as seen in our patient. Uremic leontiasis ossea is characterized by significant hypertrophy of the jaws with serpiginous "tunneling" or channeling within the bone and poor visualization of the cortical bone [8]. Thus, hyperparathyroidism secondary to chronic renal failure and hemodialysis may cause a broad range of osteodystrophic changes especially in skull and facial bones leading to a rare phenomenon named uremic leontiasis ossea or bighead disease. Pathology reported this case as fibrous dysplasia and in such cases diagnosis is made by laboratory data and radiologic features. In mild hyperparathyroidism, skeletal changes can be microscopic such as generalized demineralization, sub periosteal resorption, bone cysts, and pathologic fractures; however, in advanced stages of the disease particularly with prolonged hemodialysis as in this case, marked facial and skeletal anomalies can be seen compressing intracranial the cavity and persistent respiratory problems. It is important to recognize features of uremic leontiasis ossea, as it may result in life-threatening upper airway obstruction and compressive cranial neuropathy while after parathyroidectomy, facial changes can be stabilized or improved mildly. Supplements of calcium and vitamin D combined with reduction of phosphate levels have been recommended to be effective. The surgical contouring of the enlarged facial bones is controversial [11]. In a case report, significant ameliorations of the patient's skull changes, including a reduced skull base, maxillary and mandibular modifications, occlusal correction and a recovery of the lamina dura of the alveolar bone, were achieved following surgical and symptomatic drug treatment [2]. Ultimately, early recognition of incipient uremic leontiasis ossea clinically and on imaging is essential to prevent progression to severe disfigurement that can result from prolonged untreated secondary hyperparathyroidism [12]. 


\section{References}

[1] Taskapan, H., Taskapan, C., Baysal, T., Sahin, I., Ulu, R., Karadag, N. and Kirimlioglu, V. (2004) Maxillary Brown Tumor and Uremic Leontiasis Ossea in a Patient with Chronic Renal Insufficiency. Clinical Nephrology, 61, 360-363. http://dx.doi.org/10.5414/CNP61360

[2] Duan, S.Y., Xing, C.Y., Yang, G., Wang, N.N. and Zhang, B. (2014) Dramatic Alteration of the Skull in a Uremic Patient with Leontiasis Ossea. Internal Medicine, 53, 1971-1976. http://dx.doi.org/10.2169/internalmedicine.53.2217

[3] Maramattom, B.V. (2006) Leontiasis Ossea and Post Traumatic Cervical Cord Contusion in Polyostotic Fibrous Dysplasia. Head \& Face Medicine, 2, 24. http://dx.doi.org/10.1186/1746-160X-2-24

[4] Lee, V.S., Webb Jr., M.S., Martinez, S., McKay, C.P. and Leight Jr., G.S. (1996) Uremic Leontiasis Ossea: “Bighead” Disease in Humans? Radiologic, Clinical and Pathologic Features. Radiology, 199, 233-240. http://dx.doi.org/10.1148/radiology.199.1.8633151

[5] Bringhurst, F.R., Demay, M.B. and Kronenberg, H.M. (2003) Hormones and Disorders of Mineral Metabolism. In: Larsen, P.R., Kronenberg, H.M., Melmed, S., et al., Eds., Williams Textbook of Endocrinology, 10th Edition, Elsevier, Philadelphia, 1323-1324.

[6] Rosenberg, A.E. (2005) Bones, Joints and Soft Tissue Tumors. In: Kumar, V., Abbas, A.K. and Fausto, N., Eds., Robbins and Cotran Pathologic Basis of Disease, 7th Edition, Elsevier, Philadelphia, 1287-1288.

[7] Michiwaki, Y., Michi, K. and Yamaguchi, A. (1996) Marked Enlargement of the Jaws in Secondary Hyperparathyroidism: A Case Report. International Journal of Oral and Maxillofacial Surgery, 25, 54-56. http://dx.doi.org/10.1016/S0901-5027(96)80012-9

[8] Chang, J.I., Som, P.M. and Lawson, W. (2007) Unique Imaging Findings in the Facial Bones of Renal Osteodystrophy. American Journal of Neuroradiology, 28, 608-609.

[9] Raisz, L.G., Kream, B.E. and Lorenzo, J.A. (2003) Metabolic Bone Disease. In: Larsen, P.R., Kronenberg, H.M., Melmed, S., et al., Eds., Williams Textbook of Endocrinology, 10th Edition, Elsevier, Philadelphia, 1395-1396.

[10] Kumar, S., Thuraisingham, R. and Yaqoob, M. (2006) Big-Head Disease: Uremic Leontiasis Ossea. Kidney International, 69, 1709. http://dx.doi.org/10.1038/sj.ki.5001526

[11] Damm, D.D., Neville, B.W., McKenna, S., Jones, A.C., Freedman, P.D., Anderson, W.R. and Allen, C.M. (1997) Macrognathia of Renal Osteodystrophy in Dialysis Patients. Oral Surgery, Oral Medicine, Oral Pathology, Oral Radiology, and Endodontology, 83, 489-495. http://dx.doi.org/10.1016/S1079-2104(97)90151-7

[12] Haroyan, H., Bos, A. and Ginat, D.T. (2015) Uremic Leontiasis Ossea. American Journal of Otolaryngology, 36, 7476. http://dx.doi.org/10.1016/j.amjoto.2014.08.007 